\title{
Teaching Occupational Health and Safety in Engineering Schools - Best Practices, Support, and Opportunities
}

Graeme Norval, P.Eng. Department of Chemical Engineering and Applied Chemistry University of Toronto Graeme.norval@utoronto.ca

Tony Pasteris , P.Eng. Minerva Canada 5110 Creekbank Road Mississauga, Ontario, L4W 0A1

Pasteris@rogers.com

\section{Abstract}

With the current pace of retirements, more engineers are being fast-tracked into operating positions where Safety, Health and Environment (SHE) is an important and vital component of their work. Educators are beginning to hear more and more from industry and government that there is a need for engineers to be better educated in SHE Management as well as Process Safety Management.

Minerva Canada Safety Management Education Inc. is a not for profit organization dedicated to promoting the teaching of SHE Management education to post-secondary teaching institutions across Canada. It targets the educators of tomorrow's leaders by encouraging colleges and universities to embed SHE Management education into the core curricula of business and engineering schools.

Since 2004, there have been 140 engineering professors from 26 Canadian universities that have attended Minerva's annual Summer Institute. Professors have been provided with valuable presentations and teaching material at these Institutes on various aspects of Safety, Health and Environment from members of industry, government, H\&S associations and academia.

At the June 2010 CEEA Conference, the authors of this paper will present the compelling case for the need for more SHE education in our engineering schools, from a business, regulatory and ethical standpoint. They shall also discuss recent changes in the Canadian Engineering Accreditation Board requirements and what this may mean to engineering curriculum requirements. Finally, the authors will discuss the inventory of SHE teaching material that is available free from Minerva's Summer Institutes and
Vic Pakalnis, P.Eng.

Robert M. Buchan Department of Mining

Queen's University

pakalnis@queensu.ca its website along with teaching methods to incorporate some of it into existing courses.

\section{Introduction}

The "practice of professional engineering" means any act of designing, composing, evaluating, advising, reporting, directing or supervising wherein the safeguarding of life, health, property or the public welfare is concerned and that requires the application of engineering principles, but does not include practising as a natural scientist [1]. Responsible Care ${ }^{\circledR}$ is the chemical industry's global voluntary initiative under which companies, through their national associations, work together to continuously improve their health, safety and environmental performance, and to communicate with stakeholders about their products and processes. One key element is the requirement to adopt management systems following the elements of Plan-Do-Check-Act.

Leadership and Management of Change are important elements of any management system. The most successful organizations recognize that changes in personnel requires leadership commitment to provide the necessary training resources and that the change must be handled using a management of change approach.

The current generation of safety managers came into organizations as Responsible Care ${ }^{\circledR}$ was being developed. It was common practice for junior engineers to have a senior engineering mentor. The junior engineers had time to learn before acquiring higher levels of responsibility.

The manufacturing environment is now quite different; corporations are more streamlined and outsource products to smaller specialized companies. Each organization has fewer engineers. Indeed, it is 
not uncommon for graduating engineers to be hired into small companies where they are the sole engineer on staff.

At the same time, societal demands on companies have increased. There are more and more varied regulations pertaining to environment and health and safety. Today's engineering graduates have more responsibility and less time to acquire the knowledge. It is apparent that improved training must occur during the university years.

\section{Background}

\subsection{Young Worker Statistics}

Young workers (15 to 24 years of age) account for $17 \%$ of Ontario's workplace injuries [2]. For most of these years, the young workers are students. Young workers are far more prone to have workplace accidents than older workers.

In response to this, the Ministry of Labour and Workplace Safety and Insurance Board have created the Young Worker Awareness Safety Program which includes an interactive web site, training and other resources [3].

These products have been introduced into some high schools, and some young workers have been exposed to the material. The lack of change in injury rates demonstrates that continued effort is needed.

Young workers need to acquire better knowledge and skills around safety, health and environment during their secondary and post secondary education including changing their behaviour towards injury prevention for themselves and for their fellow workers.

\subsection{NIOSH’s Project Minerva}

The importance of educating future business leaders in the fundamentals of Health and safety was recognized in the 1980's. NIOSH created Project MINERVA, which was an effort to introduce occupational health and safety education into business school curriculum [4]. Indeed, a curriculum was developed for this purpose [5]. Unfortunately, the initiative sputtered in the United States.

Figure 1. Project Minerva Curriculum

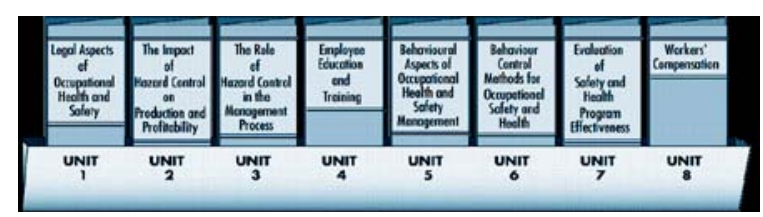

\subsection{Minerva Canada}

Of the partners in Project Minerva, only the Canadian entities remain. Minerva Canada is a notfor-profit organization focused on promoting Health and Safety Education in post secondary teaching institutions. It is a volunteer organization consisting of academia, government industry and trade associations. The industrial support includes Dupont, Imperial Oil, General Motors, Bruce Power, Trimac, among the other leading organizations behind Minerva Canada. These companies are involved in a disparate set of industries, chemical, petroleum, automotive, nuclear and transportation.

The first Summer Institute was run in 2004, in partnership with the Process Safety and Loss Management Divisions of the Canadian Society for Chemical Engineering and the Chemistry Industry Association of Canada. Since that time, more than 140 engineering professors from 26 post secondary institutions have attended. The goal of the Summer Institutes is both to educate the educators as well as to get educational resources into the hands of the educators.

\subsection{The Educational Literature}

There is a wealth of information available on the subject of health and safety and environmental management. Most of this is focused on the engineering community. For example, The Center for Chemical Process Safety (a corporate organization within AIChE) has published numerous texts in both hardcover and electronic formats, many of which are guidelines [6].

The Institution of Chemical Engineers (IChemE) has a different series of texts as well as safety animations [7]. In addition, IChemE publishes the Trevor Kletz collection covering "HAZOP and HAZAN" [8], and “An Engineer's View of Human Error” [9].

Both organizations provide free educational resources. The Process Safety Beacon is a monthly epublication, and IChemE has Loss prevention Bulletin which is a bimonthly journal with downloadable case studies [11].

In short, there is a wealth of technical information available to support the training of student engineers. The material has been written by practicing engineers, it has simple mathematics and worked practical examples. The reason for so little safety education in the undergraduate engineering curriculum is not due to the lack of available information and resources 


\subsection{Accreditation}

The Canadian Engineering Accreditation Board has recently added the subject of Risk Management to the Graduate Attributes.: "Design: An ability to design solutions for complex, open-ended engineering problems and to design systems, components or processes that meet specified needs with appropriate attention to health and safety risks, applicable standards, and economic, environmental, cultural and societal considerations" and "Economics and project management: An ability to appropriately incorporate economics and business practices including project, risk, and change management into the practice of engineering and to understand their limitations". [12]. It is clear that an understanding of Risk and Safety is now being better defined as an integral component of an engineer's education.

\subsection{A Difference in Cultures}

It is difficult to explain a culture to people who have never experienced it. Dupont is typical of the chemical industry, and Klein has described their 200+ year history of safety in North America [13]. The original site (Brandywine) produced gunpowder, and had buildings spaced apart, with light gauge roofs that directed blasts away from buildings and workers, as well as using redundant safety valves. The company instituted safe work instructions and safety commissions at the turn of the last century. In the 1920's Irenee DuPont noted that practically all accidents are avoidable, and established a goal of no accidents. The core value of safety was established by E.I. DuPont and still remains.

The Conference Board of Canada has recently published a briefing note on building commitment to health and safety transformation within organizations, noting that such change must begin with the CEO [14]. The CEO must develop a clear understanding of the organization's risk environment, its effect on employee health and safety, and the potential consequences for the business.

This theme is also included as the first element of Process Safety Management [15, 16] - Accountability. The other key elements of a PSM culture include: Process Knowledge and Documentation, Capital Project Review and Design procedures, Process Risk Management, Management of Change, Process and equipment Integrity, Human Factors, Training and Performance, Incident Investigation, Standards, Codes and Regulations, Audits and Corrective Actions and Enhancement of Process Safety Knowledge. These 12 management principles tie very well to an engineering education.

\subsection{Business Results Through Health and Safety}

Businesses that have implemented effective processes and systems for managing health and safety have done so not only because of care and concern for the employees, but because it makes good business sense [17]. Their business justifications include:

The need for Compliance with the law; leading organizations treat legal requirements as minimum standards for business operations;

Cost Reduction (personnel, WSIB premiums, production maintenance and legal);

Protecting against business interruptions;

Improving employee relations;

Improving reliability and productivity;

Building public trust;

Building organizational capability.

Today's engineer needs to better understand the moral, ethical, legal and business issues in properly managing safety, health and environment related to these areas as one day they will be the plant manager and/or CEO of a corporation.

\section{Curriculum SHE Content}

\subsection{Safety for all Engineering Students}

The starting point for an engineer's safety education should be with Hazard Identification. A hazard is a chemical or physical property or condition that has the potential of causing damage or any kind of harm to a receptor. Common hazards include elevation, motion, electricity, pressure and chemical energy. Engineers recognize these as sources of potential energy; engineering educators recognize these as the First Year Curriculum.

Most engineering schools have a first year design course. Discussion should start with injury statistics: 100 on the job fatalities with 250 work related fatalities each year in Ontario, and 300,000 lost time injuries [18]. In Ontario, the direct cost of a lost time injury is $\$ 28,700$ [19], with indirect costs (payable by the business) estimated at four times that. Dispel the myth that it is cheaper to have an injury than to prevent it. Indeed, well run organizations are amongst the leaders in health and safety performance [17]

All engineering student need to be introduced to the key components of the Occupational Health and Safety Act: the internal responsibility system, the right to know and the right to refuse unsafe work. In addition, WHMIS must be taught. The Ministry of 
Labour has created e-learning that provides this education and has a 100 question test after completion [20].

Figure 2: Worksmart e-campus

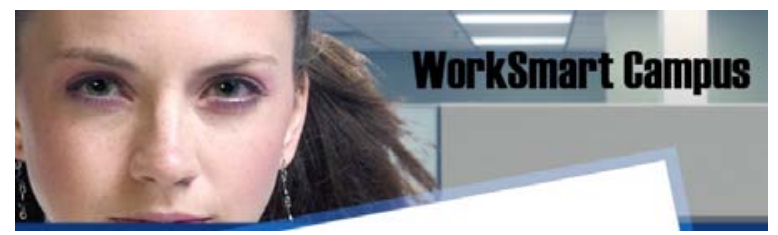

\subsection{Understanding Risk}

All students need to understand the concept of Risk. Risk is a measure of injury, damage or loss in terms of event likelihood and magnitude - in essence, the product of hazard consequence (\$ or fatalities pre event) and the probability or frequency (events per annum).

Hazards are then identified (height or speed of an object, charge on a capacitor, pressure and volume of a container, amount of chemical). A mechanism to release the potential energy is identified, and the event is quantified (how much energy is released and how far does a part fly). This is the hazard quantification.

Event frequency is given by probability theory. The probability, $\mathrm{P}(\mathrm{t})$, that a part will fail in the interval $(0, \mathrm{t})$ is

$$
P(t)=1-e^{-\mu t}
$$

where $\mu$ is the constant failure rate.

A Layer of Protection can be inserted to reduce the probability and/or the consequence of the event. Layers of Protection are fallible, and the probability of an event that is the result of a series of independent steps is either

$$
P=\prod_{1}^{n} P_{i} \text { or } P=\sum_{i}^{n} P_{i}
$$

depending on the set of logical AND and OR functions in the case.

The probability of failure increases with the mean time between testing

$$
\left.P=\lambda\left(T_{F} / T_{G}\right)\right\}
$$

where $\lambda$ is the normal failure on demand at a test frequency of $T_{G}$, and $T_{F}$ is the real testing frequency.

The probabilistic side of Quantitative Risk Analysis is a perfect fit for any engineering statistics course. In addition, it is an important application of Event Trees or Fault Trees.
Figure 3: Reason’s Swiss Cheese Model [21]

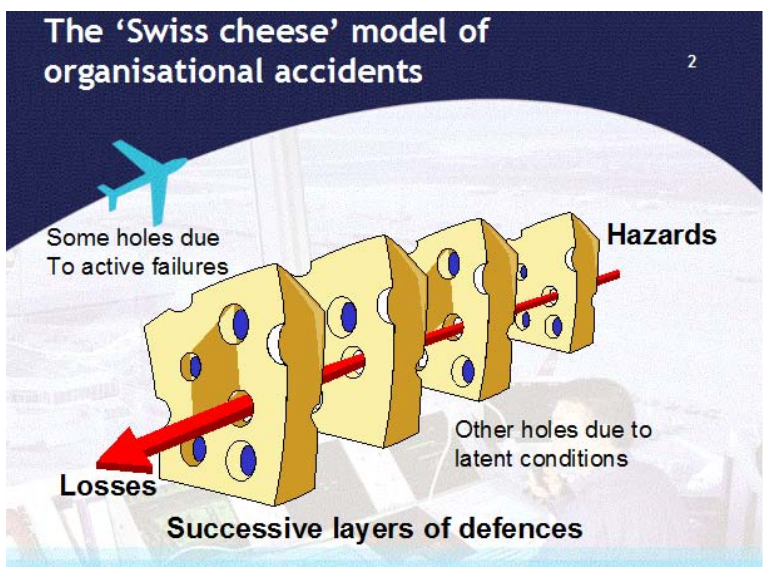

\subsection{Chemical Engineering Specific Information}

The chemical and petroleum industries have well established management systems for Environmental, Health and Safety. Chemical engineering students need an enhanced understanding of these and the management systems related to fires, explosions and toxicity.

Chemical plants have source models that are well established. The rate of a leak is an orifice equation,

$$
Q_{m}=A C_{o} \sqrt{2 \rho P}
$$

where $Q_{m}$ is the mass flowrate, $A$ is the crosssectional area of the hole, Co is the discharge coefficient, $\rho$ is the density and $\mathrm{P}$ is the gauge pressure.

The fraction of the material that flashes $\left(f_{v}\right)$ following a release is a thermodynamic equation for liquefied gases:

$$
f_{v}=\frac{C_{p}\left(T_{o}-T_{b}\right)}{\Delta H_{v}}
$$

where $C_{p}$ is the heat capacity, $T_{o}$ is the initial temperature, $\mathrm{T}_{\mathrm{b}}$ is the normal boiling point and $\Delta \mathrm{H}_{\mathrm{v}}$ is the ;latent heat of vapourization (this expression assumes constant physical properties).

The rate of volatilization from a spill is a heat transfer equation proportional to spill area and temperature difference between the ground and the liquid, or a mass transfer equation proportional to vapour pressure:

$$
Q_{m}=\frac{M K A P_{v}}{R T}
$$

where $M$ is the molecular weight, $K$ is the mass transfer coefficient, $P_{v}$ is the vapour pressure at temperature $\mathrm{T}$ and $\mathrm{R}$ is the gas constant. 
Not only is it possible to have Health and safety examples in the core chemical engineering courses, S.A.Ch.E. (Safety and Chemical Engineering Program) has developed a series of example questions with answers for the very purpose [22]. Most Canadian Chemical Engineering departments are S.A.Ch.E. members. In addition, S.A.Ch.E. offers a Certificate of Safety Achievement to students that complete a 5 lecture module, each of which has a test (and who are A.I.Ch.E. members).

\subsection{The Minerva Curriculum}

The Minerva 2-Day Summer Institute has no registration fee; attendees are expected to cover their own transportation and incidental costs. Minerva creates the curriculum, invites the speakers, and collects several CD's of teaching material that is provided to each attendee. Speakers come from industry and government, and provide the background material and context required for the Health and Safety material. The speakers also are available for consultation during the year to answer specific questions.

Figure 4: Industrial Human Factors Example

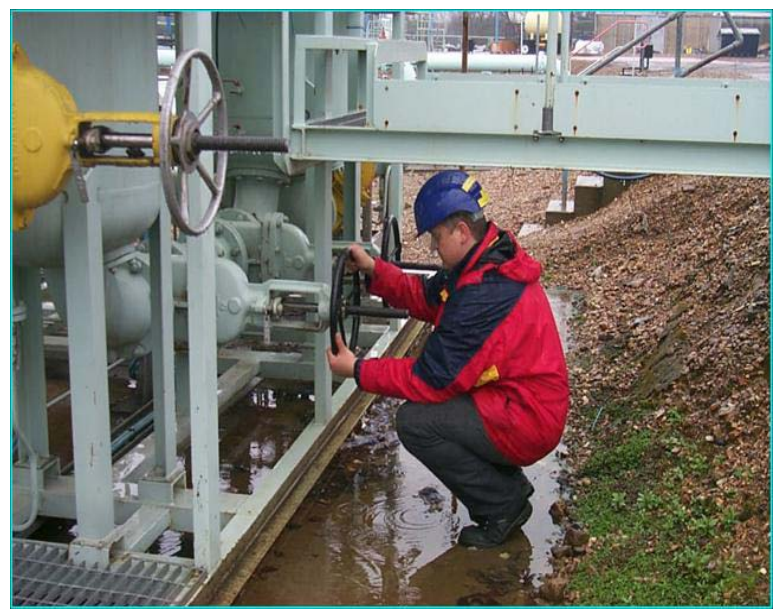

The above photograph shows an example of workplace design, whereby the surroundings make it inherently difficult to perform the task. The presentations as well as Case Studies are available at the Summer Institute as well as through the Minerva website [23].

For example, the University of Ontario Institute of Technology prepared a case study of the impact of GM's safety system enhancements in reducing their employee injuries [23]. Figure 5 shows the improvement in lost time performance. In 1994, the GM (Oshawa) truck plant had a loss time injury rate
(LTI) of 13. This means that each year 13 workers out of every 100 would suffer an injury at the workplace and miss at least 1 shift. The provincial average is 1.9. Through changing their culture, the GM truck plant was able to reduce the LTI to less than 0.5

Figure 5: Change in GM Lost Work Performance

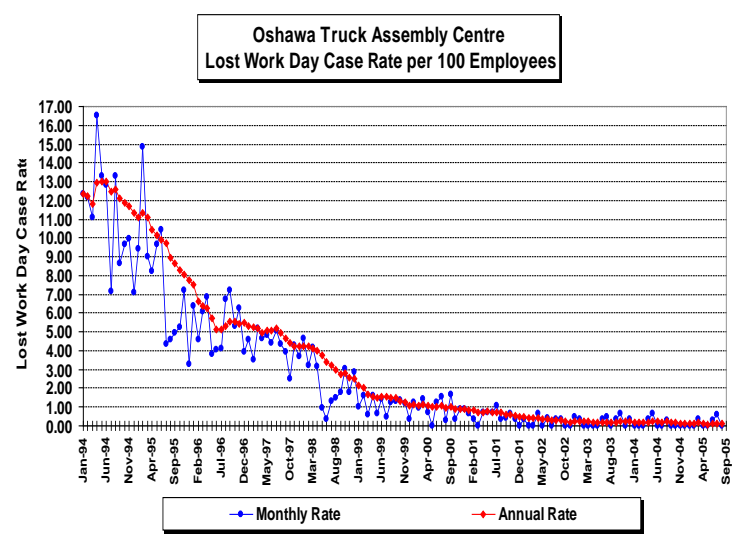

Each Summer Institute has a workshop in which best practices are shared. There is now a network of professors teaching this material and exchanging ideas and teaching methods that work.

\subsection{Conclusions}

This paper describes the need for improved Health and Safety curriculum for engineering students. The content is consistent that proposed in the UK [24]. To be effective, this material needs to be taught in small pieces in a variety of courses throughout the curriculum, and through the interaction of industry, government and academia. [25]. Government and industry have worked (through Minerva) to train professors in the fundamentals of Health and Safety for the past decade. This initiative needs to grow from chemical engineering into the other disciplines. The need is greater today than when this matter was first raised by Talty [26] and then again by Levitsky [27], 25 years ago.

It is important to recognize that faculty are not expected to be expert in the material. Teaching resources have been created by a variety of government, trade association and industries [22, 23]. Bringing these materials into the classroom will enhance the student's learning. Minerva works to provide these materials for professors, and to make them more familiar with the Health and Safety curriculum, to improve graduating student's knowledge of these topics. Using these materials will enhance the curriculum and satisfy accreditation 
needs, but more importantly, the higher level of understanding required for tomorrow's global leaders. 


\section{References}

[1] “Professional Engineer’s Act”, R.S.O. 1990, last amendment 2009.

[2] "Young Worker Statistics”, Workplace Safety and Insurance Board, 2008.

[3] vide http://www.youngworker.ca/en/; "First Four Weeks Health \& Safety Orientation and Training, IAPA, 2008.

[4] Wegman, D.H. and Fine, L.J., "Occupational Health in th e1990's”, Annu. Rev.Public Health 11 89103 (1990).

[5] Rudge, J., "Safety and Health Training of Managers", in Encyclopedia of Occupational Health and Safety, International Labour Organization, S18.18, Geneva, 1998.

[6] for example "Guidelines for Process Safety Fundamentals in General Plant Operations", Wiley, New York, 1995.

[7] “Publications Catalogue”, IChemE, Rugby, UK, 2010.

[8] Kletz, T., "HAZOP and HAZAN", $4^{\text {th }}$ Ed, IChemE, Rugby, UK, 1999.

[9] Kletz, T., “An Engineer's View of Human Error”, $3^{\text {rd }}$ Ed, IChemE, Rugby, UK, 2001.

[10] Process Safety Beacon, Center for Chemical Process Safety, AIChE, New York.

[11] Loss Prevention Bulletin (bimonthly journal, IChemE, Rugby, UK.

[12] “Accreditation Criteria and Procedures", Engineers Canada, 2009.

[13] Klein, J.A., "Two centuries of Process Safety at DuPont”, Process Saf. Prog. 28114 (2009).
[14] Munn-Venn, T and Rutten, B., "How CEOs can Tranform Health and Safety", Conference Board of Canada Insight, publication 08-320, 2008.

[15] "Process Safety Management” $3^{\text {rd }}$ Ed, C.S.Ch.E. 2002.

[16] "Guidelines for Risk Based Process Safety", Wiley, New York, 2007.

[17] "Business Results Through Health and Safety", WSIB and CMEA, 2001.

[18] "Statistics", Workplace Safety and Insurance Board, 2008.

[19] "2010 Premium Rates”, Workplace Safety and Insurance Board, 2010.

[20] http://vubiz.com/chaccess/worksmart/.

[21] Reason, J., Hollnagel, E., and Paries, J., "Revisiting the Swiss Cheese Model of Accidents", EEC Note 13/06, 2006.

[22] http://www.sache.org/.

[23] http://www.safetymanagementeducation.com

[24] "Integrating Risk Concepts into Undergraduate Engineering Courses”, UK Health and Safety Executive, 2009.

[25] Paklanis, V., "For Safety's Sake: An act worth celebrating", Canadian Government Executive, October 2009.

[26] Talty, J.T., "Integrating Safety and Health into Engineering School Curriculum”, Chem. Eng. Prog. 82 13-16 (1986).

[27] Levitsky, J.J, "Safety, Health and Loss Prevention in the Undergraduate Chemical Engineering Curriculum”, Plant Op. Prog. 7 190-194 (1988). 